Trong nghiên cứu tổng quan hệ thống so sánh hiệu quả tiệt trừ $\mathrm{H}$. pylorri của phác đồ 3 thuốc có levofloxacin và phác đồ $\mathrm{OAC}$ truyền thống, sử dung trong 10-14 ngày cho thấy hiêu quả tiệt trừ H.pylori vượt trội (90\% so với $73 \%)$ của phác đồ có levofloxacin. Việc sử dụng thêm thuốc Bismuth trong phác đồ 3 thuốc có levofloxacin giúp gia tăng hiệu quả tiệt trừ vi khuẩn.

Tỷ lệ đơn thuốc chưa hợp lý chiếm 29,2\%, chủ yếu là một vấn đề chưa hợp lý $(22,9 \%)$. Sứ dụng liều dùng các thuốc chưa hợp lý là những vấn đề phổ biến, đặc biệt là với liều dùng của bismuth $(60,7 \%)$. Tổng số lỗi ghi nhận được trong nghiên cứu của Sayers YM và cộng sự là 672 lỗi trong số 491 đơn thuốc. Tỷ lê các loại sai sót có sự khác biệt rõ rệt giữa các nghiên cứu. Nghiên cứu của tác giả Anthony J Avery và cộng sự cho thấy tỷ lệ sai sót cao hơn là $4,1 \%$ (247/6048; $95 \%$ CI $=3.6 \%-4.6 \%)$, trong đó sai sót về không đầy đủ thông tin trong đơn thuốc chiếm tỷ lệ cao nhất. Các sai sót về chỉ định được chia ra cụ thể (sai thuốc, chống chỉ định,...) trong nghiên cứu của Avery AJ. và cộng sự, nhưng nhìn chung tỷ lệ này thấp hơn so với tỳ lệ thu được trong nghiên cứu của chúng tôi.

Các bác sĩ ngoại khoa có xu hướng kê đơn thuốc điều trị $\mathrm{H}$. pylori chưa hợp lý cao hơn so với các sĩ nội khoa. Điều này có thể giải thích do thực tế việc điều trị $H$. pylori là liệu pháp điều trị nôi khoa, các bác sĩ nội được câp nhât thông tin điều trị nội khoa thường xuyên hơn. Do đó, cần triển khai các buổi đào tao liên tự về các vấn đề điều trị nội khoa cho các bác sĩ giúp nâng cao tính hợp lý trong kê đơn thuốc.

\section{KẾT LUÂ̂N}

Việc kê đơn thuốc điều tri $H$. pylori chưa hợp lý còn tương đối cao. Cần cập nhật liên tục các hướng dẫn điều trị $\mathrm{H}$. pylori thường xuyên giúp các bác sĩ kê đơn thuốc hợp lý, từ đó nâng cao hiệu quả điều trị cho bệnh nhân.

\section{TÀI LIỆU THAM KHẢO}

1. Eusebi L. H. et al. (2014), "Epidemiology of Helicobacter pylori infection". Helicobacter, 19(1), pp.1-5.

2. Varocha M. et al. (2018), "Helicobacter pylori management in ASEAN: The Bangkok consensus report". Journal of Gastroenterology and Hepatology, 33, pp. 37-56.

3. Malfertheiner $P$, et al. (2017), "Management of Helicobacter pylori infection-the Maastricht V/Florence Consensus Report". Gut, 66, pp.6-30.

4. Pounder RE et al. (1995), "The prevalence of Helicobacter pylori infection in different countries". Aliment Pharmacol Ther, 9(2), pp. 33.

5. Torres J, et al. (1998), "A community-based seroepidemiologic study of Helicobacter pylori infection in Mexico". J Infect Dis, 178, pp. 1089.

6. Binh TT, et al. (2012), "The incidence of primary antibiotic resistance of Helicobacter pylori in Vietnam". J Clin Gastroenterol, 47(3), pp. 233-238.

7. Yamaoka Y, et al. (2015), "Appropriate first-line regimens to combat Helicobacter pylori antibiotic resistance: an Asian perspective". Molecules (Basel, Switzerland), 20(4), pp. 6068-6092.

8. Malekzadeh R, et al. (2014), "Helicobacter pylori eradication in West Asia: a review". World journal of gastroenterology, 20(30), pp. 10355-10367.

9. Choi M, et al. (2021), "Korean College of Helicobacter and Upper Gastrointestinal Research. Evidence-Based Guidelines for the Treatment of Helicobacter pylori Infection in Korea 2020". Gut Liver, 15(2), pp. 168-195.

\title{
THƯ⿱C TRANG SỨC KHỎE TINH THẦn CỦA NHÂN VIÊN Y TẾ THAM GIA CÔNG TÁC PHÒNG CHỐNG DİCH BỂNH VIÊM ĐƯờNG Hô HẤP CẤP (COVID-19) Ở' MộT Số BỆNH VIÊ̂N TẠI HÀ NộI NĂM 2020
}

\author{
Bùi Thị Thanh Vân' ${ }^{1}$, Nguyễn Thị Bích Ngọc ${ }^{\text {, }}$ \\ Trần Nguyễn Ngọc $^{2}$, Đào Đức Thao ${ }^{2}$, Nguyễn Hoàng Thanh ${ }^{2}$ \\ TÓM TẮT \\ Năm 2020 đánh dấu sư xuất hiên của đai dich \\ COVID-19 trên toàn thế giới, đại dịch đã ảnh hưởng \\ lớn đến tâm lý của tất cá mọi người, đặc biệt là các \\ ${ }^{1}$ Bệnh viện Trung ương Quân đội 108 \\ 2 Trường Đại hoc Y Hà Nối \\ Chịu trách nhiếm chính: Bùi Thị Thanh Vân \\ Email: btvan118@gmail.com \\ Ngày nhận bài: 23.2.2021 \\ Ngày phản biên khoa hoc: 26.3 .2021 \\ Ngày duyệt bài: 7.4.2021 \\ nhân viên y tế ở tuyến đầu chống dịch. Mục tiêu của \\ nghiên cứu là xác định tỷ lệ lo âu, stress và trâm cảm \\ và các yếu tố liên quan đển tỷ lệ lo âu, stress, trâm \\ cảm của NVYT tham gia phòng/ chống dịch bênh \\ COVID-19. Nghiên cứu mô tả cắt ngang trên 87 NVYT \\ từ tháng 3 - tháng 6/ năm 2020.Kết quả cho thâytỷ lê \\ nhân viên y tế tham gia phòng chống dịch COVID-19 \\ tai một số bênh viên tham gia nghiên cứu có biểu hiên \\ lo âu, stress và trầm cảm lần lượt là $19,5 \%, 8 \%$ và \\ $5,7 \%$. Tỷ lê stress, lo âu, trầm cảm có liên quan đến: \\ thời gian tham gia phòng/chống dịch $(p<0,05)$, tình \\ trang hôn nhân và nghề nghiệp. Nghiên cứu giúp các \\ nhà quản lý có các chính sách để cải thiện, nâng cao
}


hiệu suất, bảo vệ nhân viên y tế tại tuyến đâu chống dịch.

Tư khóa: COVID-19, Sức khỏe tinh thân, NVYT tham gia phòng chống dịch

\section{SUMMARY \\ MENTAL HEALTH OF HEALTH WORKER WHO PARTICIPATED IN COVID-19 EPIDEMIC PREVENTION/CONTROL AT SOME HOSPITALS IN HANOI, 2020}

The year 2020 marks the pandemic of the COVID19 epidemic around the world; it has a great impact on the psychology of all people, especially the health workers at the frontline. The objective of the study is to determine the prevalence of anxiety, stress and depression and factors related to rates among Health worker who participate in COVID-19 epidemicprevention/ control. The study design is cross-sectional. It collected data on 87 health workers from March to June 2020. The results showed that the prevalance of anxiety, stress and depression on health workers who participate in COVID-19 epidemic prevention/control were $19.5 \%, 8 \%$ and $5.7 \%$, respectively. The rates of stress, anxiety, and depression were related to: duration of participation in epidemic prevention/control $(p<0.05)$, marital status and occupation. Research helps managers to adopt policies to improve, improve efficiency, and protect front-line health workers against epidemics.

Keywords; COVID-19, Mental health, Health worker

\section{I. ĐĂT VẤN ĐÊ}

Đại dich COVID-19 là bênh truyền nhiễm nguy hiểm với tác nhân gây bênh là SARS-CoV$2^{[1]}$. Dịch bệnh đã nhanh chóng lây lan và trở thành đại dịch toàn câu, xuất hiện ở hơn 200 quốc gia và vùng lãnh thổ trên thế giới, khoảng 90 triệu người nhiễm, gần 2 triệu người tử vong [2]. Tổ chức $Y$ tế Thế giới (WHO) đã phải tuyên bố COVID-19 là tình trạng khẩn cấp y tế công cộng toàn cầu, là mối quan tâm lớn của thế giới [3]. Trước đai dịch diễn ra trên toàn cầu, áp lực lên nhân viên y tế rất nặng nề đặc biết các nhẩn viên y tế tham gia công tác phòng/chống dịch bệnh. Họ không chỉ chịu áp lực lớn về tâm lý mà còn có nguy cơ nhiếm bệnh rất cao.Một nghiên cứu gần đây do nhóm nghiên cứu của Thạc sĩ Jianbo Lai, Đại học Y khoa Chiết Giang, Hàng Châu, Trung Quốc cho thấymột nửa số NVYT được hỏi có biểu hiên của những triệu chứng trầm cảm, $45 \%$ có triệu chứng lo âu, $34 \%$ có triệu chứng mất ngủ và $72 \%$ cho thấy đang phải chịu đựng những đau buồn tâm lý [4]. Theo trang The Guardian (Anh), đai dich COVID-19 đang ảnh hưởng nghiêm trọng đến sức khỏe tinh thần của những nhân viên làm việc tại dịch vụ $Y$ tế Quốc gia (NHS), 50\% trong số 996 nhân viên y tế được khảo sát trên khắp Vương quốc Anh cho biết sức khỏe tâm thần của họ đã xấu đi kể từ khi virus SARS-CoV-2 bùng phát.

Hiện tại ở Việt Nam chưa có nhiều nghiên cứu về COVID-19, đăc biêtt là nghiên cứu đánh giá sức khỏe tâm thần của các nhân viên y tế tham gia phòng/chống dịch. Vì vậy chúng tôi đã tiến hành nghiên cứu với mục tiêu: xác định tỷ lệ lo âu, stress và trầm cảm và một số yêu tố liên quan ở các NVYT tham gia phòng/chông dich bệnh viêm đường hô hấp cấp (COVID-19) tại một số bênh viênn ở Hà Nôii năm 2020.

\section{II. ĐỐI TƯƠNG VÀ PHƯƠNG PHÁP NGHIÊN CỨU}

Đối tượng nghiên cứu: Các NVYT tham gia công tác khám sàng lọc bệnh nhân có dấu hiệu viêm đường hô hấp cấp (COVID-19) tại 8 bênh viênđược Sở $Y$ tế Hà Nôii phân công gồm Bắc Thăng Long, Mê Linh, Đức Giang, Thanh Nhàn, Hà Đông, Đống Đa và các NVYT điều trị bênh nhân mắc COVID-19 tại Bệnh viện Nhiệt đới Trung ương cơ sở Kim Chung.

Phương pháp nghiên cứu: Nghiên cứu mô tả cắt ngang, tiến hành từ tháng 03/2020 đến tháng 06/2020.

Phương pháp thu thập số liệu: Nhóm nghiên cứu gứi phiếu điều tra online (do giãn cách xã hội) bằng phần mềm Kotobook cho tất cả NVYT bao gồm bác sỹ, điều dưỡng viên, nhân viên chăm sóc, phục vụ tại các bệnh viện tham gia nghiên cứu.

Công cụ thu thập số liệu: Bộ công cụ được đánh giá theo thang điểm DASS 21 (Depression - Anxiety - Stress Scale)

Quản lý và xử lý số liệu: Số liệu sau khi thu thập được làm sạch và mã hóa. Phần mềm thống kê SPSS 20.0 được sử dụng để phân tích. Tỷ lệ lo âu, stress và trầm cảm của các NVYT tham gia khám sàng lọc và điều trị, chăm sóc bệnh nhân COVID-19 được xác định. Mức ý nghĩa thống kê $p<0.05$ được sử dụng trong thống kê phân tích những yếu tố liên quan.

Cỡ mẫu và chọn mẫu: Những NVYT đồng ý tham gia nghiên cứu và hoàn thành phiếu được lựa chọn vào nhóm nghiên cứu. Thực tế nhóm đã thu thập được 87 phiếu điều tra của các NVYT.

Biến số và chỉ số: Biến số thông tin chungcủa đối tượng nghiên cứu gồm:giới tính, nhóm tuổi, tình trạng hôn nhân, nghề nghiệp, trình độ học vấn, thâm niên công tác, thời gian tham gia phòng/ chống dịch. Biến số vềsàng lọc sức khỏe tinh thân theo thang điểm DASS.

Đao đức trong nghiên cứu: Nghiên cứu tuân thủ các hướng dẫn về đạo đức trong 
nghiên cứu y học. Các thông tin thu thập được mã hóa và chỉ dùng cho mục đích nghiên cứu. Không có bất cứ sự tác động can thiệp từ bên ngoài và mục đích nghiên cứu.

\section{KẾT QUẢ NGHIÊN CỨU}

3.1. Thông tin chung của đối tượng nghiên cứu

Bảng 3.1: Đăc điểm cá nhân của đôî tượng nghiên cứu

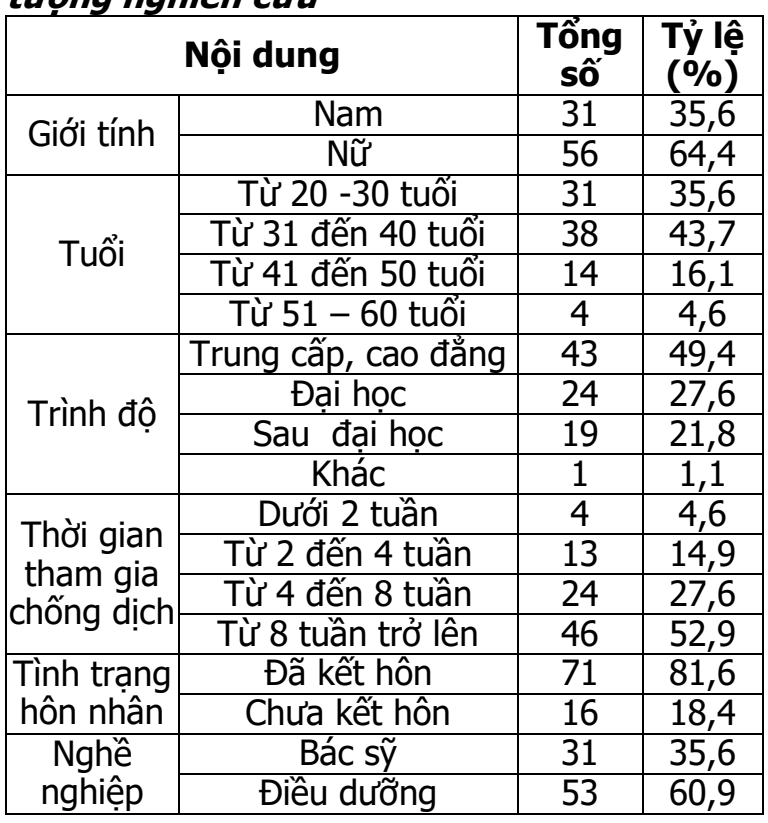

\begin{tabular}{|c|c|c|c|}
\hline \multirow{2}{*}{} & Kỹ thuật viên & 1 & 1,1 \\
\cline { 2 - 4 } & Hộ lý & 2 & 2,3 \\
\hline
\end{tabular}

Nhóm đối tượng nghiên cứu bao gồm 87 NVYT, nữ giới chiếm tỷ lệ gân gấp đôi nam giới, lân lượt là $64,4 \%$ và $35,6 \%$, đa số đều có gia đình và có con $(81,6 \%)$. Chủ yếu là có trình độ trung cấp, cao đẳng (49,4\%) trong đó phân lớn là lực lượng điêu dưỡng. Thời gian tham gia chống dịch của đối tượng nghiên cứu chủ yếu trên 8 tuân (52,9\%), thấp nhất dưới 2 tuân $(4,6 \%)$.

3.2. Thức trang sức khỏe tinh thân và một số yếu tố liên quan trên NVYT tham gia phòng/chống dịch COVID -19.

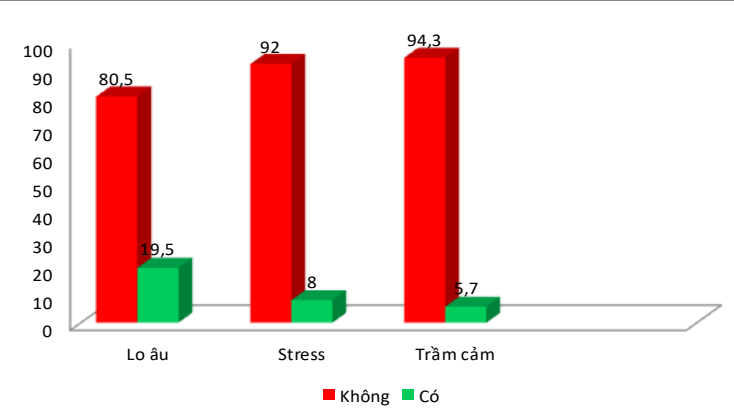

Biểu đồ 3.1. Tỷ lệ lo âu, stress, trâm cảm của NVYT tham gia phòng/ chống dịch

Biểu đồ 3.1 cho thấy dịch bệnh viêm đường hô hấp ảnh hưởng lớn đến sức khỏe tinh thân của NVYT. Trong đó tỷ lệ lo âu, stress và trâm cảm lần lượt là 19,5\%, $8 \%$ và 5,7\%.

Bảng 3.2. Tình trạng sức khỏe tinh thàn của NVYT và một số yêu tố liên quan

\begin{tabular}{|c|c|c|c|c|c|c|c|c|c|}
\hline \multirow{2}{*}{$\begin{array}{l}\text { Nội } \\
\text { dung }\end{array}$} & \multicolumn{3}{|c|}{ Lo âu } & \multicolumn{3}{|c|}{ Stress } & \multicolumn{3}{|c|}{ Trâm cảm } \\
\hline & $\begin{array}{c}\text { Có } \\
\text { n (\%) }\end{array}$ & $\begin{array}{l}\text { Không } \\
\text { n (\%) }\end{array}$ & $\begin{array}{c}\text { p- } \\
\text { value }\end{array}$ & $\begin{array}{c}\text { Có } \\
\text { n (\%) }\end{array}$ & $\begin{array}{l}\text { Không } \\
\text { n (\%) }\end{array}$ & $\begin{array}{c}\text { p- } \\
\text { value }\end{array}$ & $\begin{array}{c}\text { Có } \\
\text { n (\%) }\end{array}$ & $\begin{array}{l}\text { Không } \\
\text { n (\%) }\end{array}$ & $\begin{array}{c}\text { p- } \\
\text { value }\end{array}$ \\
\hline \multicolumn{10}{|c|}{ Giới } \\
\hline Nam & $5(29,4 \%)$ & $26(37,1 \%)$ & & $2(28,6 \%)$ & $29(36,2 \%)$ & & $1(20,0 \%)$ & $30(36,6 \%)$ & \multirow{2}{*}{$>0,05$} \\
\hline Nữ & $12(70,6 \%$ & $44(62,9 \%)$ & & $5(71,4 \%)$ & $51(63,8 \%)$ & & $4(80,0 \%)$ & $52(63,4 \%)$ & \\
\hline \multicolumn{10}{|c|}{ Độ tuối } \\
\hline $20-30$ & $10(58,8 \%$ & $21(30,0 \%)$ & \multirow{4}{*}{$>0,05$} & $5(71,4 \%)$ & $26(32,5 \%)$ & \multirow{4}{*}{$>0,05$} & $4(80,0 \%)$ & $27(32,9 \%)$ & \multirow{4}{*}{$>0,05$} \\
\hline $3-40$ & $5(29,4 \%)$ & $33(47,1 \%)$ & & $2(28,6 \%)$ & $36(45,0 \%)$ & & $1(20,0 \%)$ & $37(45,1 \%)$ & \\
\hline $41-50$ & $2(11,8 \%)$ & $12(17,1 \%)$ & & $0(0,0 \%)$ & $14(17,5 \%)$ & & $0(0,0 \%)$ & $14(17,1 \%)$ & \\
\hline $51-60$ & $0(0,0 \%)$ & $4(5,7 \%)$ & & $0(0,0 \%)$ & $4(5,0 \%)$ & & $0(0,0 \%)$ & $4(4,9 \%)$ & \\
\hline \multicolumn{10}{|c|}{ Trình độ học vấn } \\
\hline Trung cấp, & 8 & 36 & \multirow{4}{*}{$>0,05$} & 4 & 40 & \multirow{4}{*}{$>0,05$} & 4 & 40 & \multirow{4}{*}{$>0,05$} \\
\hline cao đằng & $(47,1 \%)$ & $(51,4 \%)$ & & $(57,1 \%)$ & $(50 \%)$ & & $(80,0 \%)$ & $(48,8 \%)$ & \\
\hline Đại học & $7(41,2 \%)$ & $17(24,3 \%)$ & & $2(28,6 \%)$ & $22(27,5 \%)$ & & $1(20,0 \%)$ & $23(28,0 \%)$ & \\
\hline Sau đai hoc & $2(11,8 \%)$ & $17(24,3 \%)$ & & $1(14,3 \%)$ & $18(22,5 \%)$ & & $0(0,0 \%)$ & $19(23,2 \%)$ & \\
\hline \multicolumn{10}{|c|}{ Nghề nghiệp } \\
\hline Bác sỹ & $4(23,5 \%)$ & $27(38,6 \%)$ & \multirow{4}{*}{$>0,05$} & $1(14,3 \%)$ & $30(37,5 \%)$ & \multirow{4}{*}{$<0,01$} & $0(0,0 \%)$ & $31(37,8 \%)$ & \multirow{4}{*}{$>0,05$} \\
\hline Điêu dưỡng & $12(70,6 \%$ & $41(58,6 \%$ & & $5(71,4 \%)$ & $48(60,0 \%)$ & & $5(100 \%)$ & $48(58,5 \%)$ & \\
\hline Kỹ thuật viên & $1(5,9 \%)$ & $0(0,0 \%)$ & & $1(14,3 \%)$ & $0(0,0 \%)$ & & $0(0,0 \%)$ & $1(1,2 \%)$ & \\
\hline Hộ lý & $0(0,0 \%)$ & $2(2,9 \%)$ & & $0(0,0 \%)$ & $2(2,5 \%)$ & & $0(0,0 \%)$ & $2(2,4 \%)$ & \\
\hline \multicolumn{10}{|c|}{ ian tham gia chống dich } \\
\hline
\end{tabular}


VIETNAM MEDICAL JOURNAL N²2 - APRIL - 2021

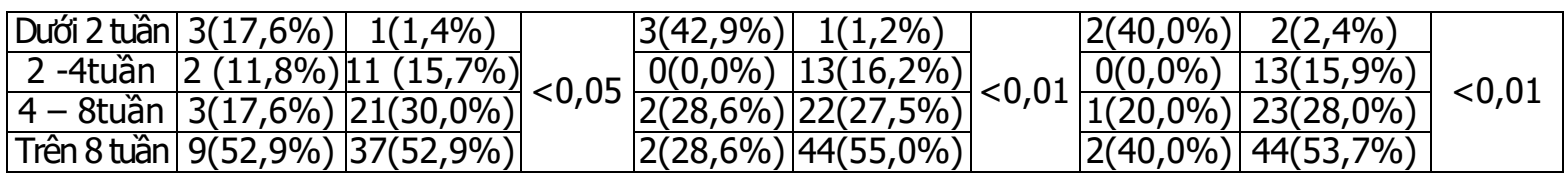

Về giới, nữ có biểu hiện trầm cảm cao hơn so với nam $(80 \%$ và $20 \%)$. Độ tuổi càng trẻ thì tỷ lệ trầm cảm càng cao, trong đó độ tuổi từ 20-30 tuổi có tỷ lệ trâm cảm cao nhất (80\%), trên 40 tuổi không có trường hợp nào có triệu chứng trầm cảm. Tỷ lệ trầm cảm chủ yếu gặp ở đối tượng điều dưỡng (chiếm 100\%) và chủ yếu ở đối tượng có trình độ trung cấp, cao đẳng (chiếm $80 \%$ ). Những người tham gia chống dịch dưới 2 tuần và trên 8 tuần có biểu hiện tình trạng trầm cảm cao hơn so với những đối tượng khác (40\%), với mức ý nghĩa thống kê $p=0,001$.

\section{BÀN LUẬN}

4.1. Đặc điểm của nhân viên y tế tham gia công tác phòng chống dịch bệnh COVID-19. Tổng số nhân viên y tể tham gia nghiên cứu là 87 NVYT với độ tuổi trung bình là 35,5 tuổi, tuổi nhỏ nhất là 26 và tuổi lớn nhất là 54. Hầu hết cán bộ nhân viên y tế thuộc nhóm tuổi từ 40 tuổi trở xuống: trong đó nhóm tuổi từ 31-40 chiếm tỉ lệ cao nhất với 43,7\%, nhóm tuổi từ 30 tuổi trờ xuống chiếm $35,6 \%$.NVYT nữ tham gia nghiên cứu chiếm $64,4 \%$, gấp 2 lần so với NVYT nam. Hầu hết trong số này thì đã lập gia đình và có con $(81,6 \%)$ nên những vấn đề lo lắng đi kèm tương đối lớn, nhất là vấn đề con cái, đối tượng chưa kết hôn chỉ chiếm 18,4\%.

Về đặc điểm công việc của đối tượng nghiên cứu tham gia công phòng/ chống dịch thì nghiên cứu chỉ ra rằng phần lớn NVYT điều dưỡng chiếm $60,9 \%$, sau đó là bác sĩ với $35,6 \%$, kỹ thuật viên là $1,1 \%$, hộ lý chiếm $2,3 \%$; phần lớn cán bộ nhân viên có trình độ học vấn ở mức trung cấp, cao đẳng $(49,4 \%)$ phù hợp với phân bố của NVYT chủ yếu điêu dưỡng. Về thời gian công tác trong ngành $\mathrm{y}$, những NVYT có tuổi nghề trên 10 năm chiếm đa số $(49,4 \%)$, sau đó là tuổi nghề từ 5-10 năm, khi tham gia phòng/chống một dịch bệnh mới nguy hiểm thì những NVYT có trình độ chuyên môn sâu, nhiều năm kinh nghiệm làm việc được lựa chọn. Thời gian tham gia phòng chống dịch chủ yếu từ 8 tuần trở lên chiếm $52,9 \%$, sau đó là từ 4-8 tuần, dưới 2 tuần chỉ chiếm $4,6 \%$; vì mục tiêu sớm đẩy lùi dịch bệnh đội ngũ cán bộ, NVYT chấp nhận cách ly, xa gia đình, người thân, sẵn sàng nhận nhiệm vụ, nguy cơ cao với trách nhiệm và mục tiêu điều trị khỏi cho người bệnh, tại sự an tâm an toàn cho cộng đồng xã hội.
4.2. Thực trang sức khỏe tinh thân của nhân viên y tế tham gia phòng/ chống dịch bệnh COVID-19. Qua kết quả nghiên cứu này có thể thây tỷ lệ lo âu, stress và trầm cảm ở nhân viên $y$ tế tham gia phòng chống dịch COVID-19 lần lượt là $19,5 \%, 8 \%$ và $5,7 \%$. Trong đó phân theo mức độ lo âu, stress và trầm cảm chúng tôi ghi nhận được: đối với tình trạng lo âu mức độ nhẹ đến nặng chiếm tỷ lệ gần ngang nhau $4,6 \%$ và $5,7 \%$, rất nặng chiếm tỷ lệ thấp hơn $(3,4 \%)$; đối với tình trạng stress mức độ vừa chiếm tỷ lệ cao hơn $(3,4 \%)$, nhẹ và nặng chiếm tỷ lệ bằng nhau $(2,3 \%)$, không có mức độ rất nặng; đối với tình trạng trâm cảm chỉ có mức độ nặng $(4,6 \%)$ và rất nặng $(1,1 \%)$. So với kết quả nghiên cứu của Thạc sỹ Jianbo Lai tại thành phố Vũ Hán thì tỷ lệ này thấp hơn nhiều ${ }^{[4]}$.Nguyên nhân do số lượng ca nhiễm tại Việt Nam thấp hơn nhiều do được kiểm soát sớm và tốt, hạn chế được sự lây lan trong cộng đồng; trong khi tại Vũ Hán là tâm dịch đầu tiên của thế giới, số lượng ca nhiễm và chết không ngừng tăng lên theo ngày, nhân viên y tế tại đây phải đối mặt với nhiêuu vấn đề nguy cấp hởn: hệ thống y tế bị quá tải, thiếu trang thiết bị bảo hộ...

Trong nghiên cứu này phần lớn đối tượng tham gia là nữ giới $(64,4 \%)$, chủ yếu là điều dưỡng $(60,9 \%)$, đây là những đối tượng chịu ảnh hưởng nhiêuu hơn, dễ có biểu hiện về các rối loạn sức khỏe tâm thần cao hơn so với những đổi tượng khác. Điều dưỡng là những người có nguy cơ phơi nhiễm cao hơn vì tiếp xúc gần gũi, thường xuyên với bệnh nhân và thời gian làm việc lâu hơn. Vì vậy tỷ lệ lo âu, stress và trầm cảm ở nữ giới gấp đôi so với nam giới. Tỷ lệ điều dưỡng có biểu hiện lo âu, stress và trầm cảm lần lượt là $70,6 \%, 71,4 \%$ và $100 \%$. Kết quả này tương đồng với một số nghiên cứu ở các nước trên thế giới, như nghiên cứu của Refai Yassen Al - Hussein và Ahmed Moshirf Al-Mteiwty (2207) sử dụng thang đo DASS 21 để đánh giá tỷ lệ nhân viên y tế bị trầm cảm, lo âu, stress tại 07 bệnh viện tại thành phố Mosul - Iran. Nghiên cứu khẳng định rẳng điều dưỡng có nhiều nguy cơ mắc các rối loạn tâm thần hớn các nhân viên y tế khác ${ }^{[5]}$. Và tại Việt Nam có nghiên cứu của Đậu Thị Tuyết (2003) đánh giá tình trạng lo âu, stress, trầm cảm của nhân viên y tế khối lâm sàng tại 2 bệnh viện cũng chỉ ra nữ giới và điều dưỡng chịu áp lực nhiều hơn các đối tượng khác ${ }^{[6]}$. 
Độ tuổi càng trẻ thì tỷ lệ lo âu, stress và trầm cảm càng cao, chủ yếu ở độ tuổi 20-30 tuổi (58,8\% lo âu, $71,4 \%$ stress, $80 \%$ trầm cảm), có thể do còn ít kinh nghiệm, chưa từng trải qua một đại dịch lớn và hoàn toàn mới nên tâm lý như vậy là điều dễ hiểu. Tuy nhiên những người có thâm niên công tác lâu (nhóm > 5 năm) lại có mức độ biểu hiện rối loạn sức khỏe tâm thân cao hơn so với nhóm < 5 nằm, chúng tôi thây có thể vì họ trải qua nhiều năm công tác, đối mă̆t với nhiều tình huống bệnh tật khác nhau, họ hiểu rõ mức độ nguy hiểm của COVID-19 với cộng đồng so với các căn bệnh khác, họ thấy được trách nhiệm to lớn của mình với người bệnh khi cả xã hội đang theo dõi từng bước đi của ngành y tế.

Kết quả nghiên cứu cho thấy tình trạng hôn nhân có mối liên quan có ý nghĩa thống kê với trạng thái lo âu $(P=0.04)$, cả với trạng thái stress và trầm cảm thì những đối tượng nghiên cứu đã kết hôn, có gia đình riêng tỷ lệ biểu hiện bệnh cao hơn nhiều so với đối tượng chưa kết hôn. Họ lo sợ lây nhiễm cho gia đình, đặc biệt lo lắng khi con cái không có người chăm sóc trong thời gian tham gia chống dịch. Cùng với đó thời gian tham gia phòng chống dịch góp phần làm tăng nguy cơ rối loạn tâm thần, có mức ý nghĩa thống kê $(P<0,05)$ với cả 3 trạng thái lo âu, stress và trầm cảm. Thời gian tham gia càng dài, tỷ lệ lo âu, stress và trâm cảm càng cao, thời gian kéo dài đồng nghĩa với việc các nhân viên y tế phải ở lại cơ quan, làm việc không có ngày nghỉ, không có thời gian chăm sóc cho gia đình, nguy cơ lây nhiễm bệnh cao hơn... những điều đó tác động lớn đến tâm lý, sức khỏe tinh thần của các nhân viên y tế.

\section{KẾT LUÂN}

Nữ giới có tỷ lệ lo âu, stress và trầm cảm cao hơn so với nam giới. Tuổi càng trẻ mức độ biểu hiện các vấn đề về sức khỏe tâm thần cũng cao hơn, chủ yếu ở độ tuổi 20-30 tuối. Điều dưỡng cũng là đối tượng chịu tác động tâm lý nhiều hơn so với các đối tượng khác.

Yếu tố liên quan có ý nghĩa thống kê với các vấn đề sức khỏe tâm thân (lo âu, stress và trầm cảm) được nghiên cứu đó là: tình trạng hôn nhân, nghề nghiệp và thời gian tham gia phòng/ chống dịch bệnh.

\section{TÀI LIÊU THAM KHẢO}

1. "Novel coronavirus (2109-nCov), Wuhan, China", www.cdc.gov, updated 16 January 2020.

2. Trang tin về dịch bệnh viêm đường hô hấp cấp CovID-19 của Bô Y tế, www.ncov.moh.gov.vn, truy cập ngăy 10/01/2021.

3. Rolling updates on coronavirus disease (COVID-19), WHO updated 11 March 2020.

4. Covid-19: "Striking" Rates of Anxiety, Depression in Healthcare Workers -Megan Brooks.

5. Yassen Al-Hussein, Ahmed Moshirf AlMteiwty (2007), "Point prevalence of Depression, Anxiety and Stress among nurses and papa-medical staff in teaching hospital in Mosul", Al-Taquani Journal, 23(5), 116-127.

6. Đậu Thị Tuyết (2012), Tình trang stress, lo âu, trẩm cảm của cán bộ y tế khối lầmsàng tai bênh viện đa khoa thành phố Vinh, bênh viên đa khoa 115 Nghệ An năm 2013và một số yếu tố liên quan, Luận văn thac sĩ quản lý bệnh viện, Đại học y tế công cộng, Hà Nội.

\title{
KẾT QUẢ PHẪU THUÂT NộI SOI KHÂU THỦNG Ổ LOÉT HÀNH TÁ TRÀNG TẠI BỆNH VIỆN BẠCH MAI GIAI ĐOẠN 2018-2019
}

\author{
Trần Mạnh Hùng ${ }^{1}$, Trần Hiếu Học ${ }^{1,2}$, Trần Quế Sơnn ${ }^{1,2}$
}

\section{TÓM TẮT}

Thủng ổ loét là một biến chứng nguy hiểm của loét hành tá tràng đòi hỏi điều trị cấp cứu ngoại khoa. Những năm gần đây, phẫu thuật nội soi khâu thủng ngày càng phổ biến mang lại kết quả tốt như nằm viên ngắn ngày, ít đau, giảm niguy cơ dính ruột, nhiểm trùng vết mổ. Mục tiêu: đánh giá kết quả phẩu thuật

${ }^{1}$ Bệnh viện Bạch mai

${ }^{2}$ Trường Đai hoc Y Hà Nôi

Chịu trách nhiệm chính: Trân Mạnh Hùng

Email: tranmanhhungngoaibm@gmail.com

Ngày nhận bài: 19.2.2021

Ngày phản biên khoa học: 29.3.2021

Ngày duyệt bài: 9.4.2021 nội soi khâu thủng ổ loét hành tá tràng Đối tượng và phương pháp: mô tả hồi cứu các bệnh nhân được phẫu thuật tại Bệnh viện Bạch Mai trong 2 năm từ 1/2018 đến 12/2019. Kết quả: 64 bênh nhân được phẫu thuật trong đó có 2 chuyển mổ mở. Ổ loét non chiếm $72,6 \%$, kích thước ổ loét từ $5-10 \mathrm{~mm}$ chiếm $85,5 \%$, khâu đơn thuân $58,1 \%$, đính mạc nối $27,4 \%$. Lượng dịch rửa trung bình $1452,3 \pm 875,2 \mathrm{ml}$. Thời gian mố trung bình là $69,3 \pm 20,1$ phút, $100 \%$ có trung tiên trong vòng $48 \mathrm{~h}$. Không có biến chứng và tử vong. Thời gian nằm viện trung bình $6,0 \pm 1,1$ ngày. Kết luân: phẫu thuật khâu thủng nội soi là phương pháp điều trị hiệu quả thủng ổ loét hành tá tràng, nằm viện ngắn ngày, không có biến chứng và tử vong.

Tư khóa: loét hành tá tràng, thủng ổ loét, phẫu thuật nội soi, khâu lỗ thủng. 